\title{
¿QUÉ TAN NATURAL ES LA INTELIGENCIA ARTIFICIAL? \\ Sobre los límites y alcances de la biomímesis computacional
}

\author{
Héctor Velázquez Fernández \\ Colegio de Bioética de Nuevo León, México
}

Resumen: En este texto se revisan los límites y alcances de la Inteligencia Artificial en función de la distinción entre habilidades deductivas racionales y hábitos intelectuales de comprensión. Bajo el entendido de que la Inteligencia Artificial imitaría y superaría las primeras, mediante la operación de máquinas racionales; mientras que quedaría lejos de y ajena a los segundos. A partir de esta distinción se puntualiza qué ejercicios intelectuales serían específicamente humanos y por qué no es posible que la Inteligencia Artificial llegue a presentar su biomímesis como algo indistinguible respecto de la inteligencia natural humana.

How Natural is the Artificial Intelligence? About limits ad scopes of computational biomimicry

Abstract: In this paper we analize the Artificial Intelligence according to the distinction between rational deductive abilities and intellectual comprehension habits. Under the understanding that the Artificial Intelligence would imitate and surpass the first ones, by means of the operation of rational machines; while it would be far and alien to the second ones. From this distinction, it is pointed out which intellectual exercises are specifically human and why it would be not possible for Artificial Intelligence to present its biomimicry as an indistinguishable result about human natural intelligence.

Keywords: Artificial Intelligence, Human Intelligence, Biomimicry.

Recibido: 03/01/2019 Aprobado: 20/02/2019

\section{Introducción}

Uno de los criterios más exitosos dentro del pensamiento occidental para distinguir cuándo hablamos de algo natural y cuándo de algo artificial fue 
adelantado por Aristóteles al abordar, a lo largo de 8 capítulos del libro 2 de su Física, los diversos matices para distinguir lo natural de lo artificial. Así, hace de lo natural aquello que posee el principio de movimiento y reposo en sí mismo, mientras que lo artificial tiene tal principio en el ser humano. Y aclara el Filósofo que cuando intentamos imitar lo natural mediante lo artificial, es importante diferenciar las artes que reproducen la naturaleza, de otras que solo intentan perfeccionarla, completarla o modificarla para bien.

Sin embargo, es difícil hoy en día pretender establecer un criterio tan tajante de diferenciación, pues podríamos hablar de que actualmente el artificio humano no solo imita, sino que a veces representa, simula, completa y hasta mejora la naturaleza en diversos aspectos; y de que no es lo mismo intentar distinguir natural de artificial cuando nos enfocamos más en el proceso que en el resultado. Combinamos infinidad de realidades fruto de la mano del hombre con el funcionamiento o devenir de procesos de origen natural: en medicina, por citar un ejemplo obvio, para la fabricación de medicamentos se requiere de la intervención artificial humana a fin de lograr la síntesis del principio activo que detone la reacción natural que devuelva la salud al organismo. La ciencia y la tecnología actual han conseguido hace años la reprogramación artificial de la actividad celular y hoy es ya un tema corriente la generación de vida artificial (Bedau, 2016).

Y podríamos seguir la lista: ¿qué tan natural puede considerarse un enriquecido alimento transgénico, ante la abundancia y proporción de los nutrientes con que ha sido enriquecido por las artes de la estequiometría? ¿Qué tan natural es la cohabitación de genes de peces en las fresas, o la luminiscencia en los gatos fluorescentes por efecto del DNA de medusas con que ha sido adicionado mediante bioingeniería? (Bensaude-Vincent, 2007: 1-21).

Aristóteles apuntaba una evidencia para entender cómo funciona la inventiva humana respecto a lo artificial: no hay nada artificial que no esté integrado de algo natural; y así de algún modo las restricciones o potencialidades de lo natural condicionan los alcances de lo artificial. No podemos 
¿Qué tan natural es la inteligencia artificial?

fabricar tijeras con papel porque no cortarían, pero podemos cultivar orejas o válvulas aórticas en la piel de un roedor, pues ello no es sino hacer crecer tejido dentro de otro tejido.

Cuando desde sus orígenes la Inteligencia Artificial (IA) se propuso potenciar las capacidades cognitivas humanas mediante su imitación, dicha mímesis se centró en las operaciones de cálculo y deducción lógica. Muy pronto la pretensión de obtener máquinas inteligentes hizo soñar en el momento en que nos sería difícil distinguir si interactuamos con humanos reales o con simples sistemas inteligentes preparados para disimular su identidad artificial.

Nos hemos acostumbrado rápidamente a la distinción entre inteligencia artificial débil (en la que se engloban todos los avances reales que la IA ha introducido en nuestra vida cotidiana), respecto de la inteligencia artificial fuerte (que pretende igualar en todas sus dimensiones, e incluso superar, a la inteligencia humana). De cualquier modo, no es siempre del todo fácil en nuestra cultura occidental comprender lo que se quiere decir con IA, pues no necesariamente se parte de una definición previa de lo que se ha de entender por inteligencia.

Pero si la IA emula en su versión débil los procesos por los que nuestra mente relaciona, calcula, enumera y transita de un conocimiento a otro, en su versión fuerte pretende igualar y superar los ejercicios más transparentes del intelecto humano. Y entonces podemos preguntarnos no qué tan artificial puede ser la inteligencia artificial, sino qué tan natural puede llegar a parecer o pretender ser. En el fondo la reflexión sobre el contraste entre natural y artificial referido a la inteligencia debería centrarse más en los límites de lo que queda fuera de esa reproducibilidad artificial, que en los alcances de lo reproducible e imitable. Porque solo entonces, en lugar de experimentar una especie de dilución de nuestra peculiaridad cognoscitiva humana que se vería imitada y hasta superada, podríamos remarcar, reconocer y, por qué no, reverenciar, si hay algo que nos haga única, especifica y singularmente humanos. 


\section{Las esferas de la IA}

En términos generales, se habla de IA cuando más allá de la imitación de procesos de cálculo, se hace referencia al estudio y reproducción del modo como el humano resuelve problemas mediante procesos de información simbólica. En este sentido son comunes las inquietudes por mantener a resguardo al ser humano cuando la IA sea tan independiente que su operatividad pudiera poner en riesgo nuestra sobrevivencia entre androides, sistemas expertos y máquinas artificiales con redes neuronales autónomas (Alfonseca, 2016).

Los sistemas de procesamiento numérico de información no simbólica, suelen dejarse fuera del concepto de IA, pues ésta designa la capacidad de abordar y solucionar problemas mediante la experiencia obtenida a partir de patrones complejos, entre otros varios recursos. Sin embargo, en una reflexión sobre qué tan natural puede llegar a mostrarse la IA, es importante recordar la diferencia entre IA débil y fuerte, para decantar si sobre lo que estamos hablando es de una mera apariencia de inteligencia o de una real emulación y eventual superación de la inteligencia humana.

Desde sus primeros rudimentos, la expectativa despertada por la IA fue llegar a reproducir los procesos inteligentes que los humanos hacemos al momento de resolver problemas. Fueron los juegos de estrategia uno de los primeros campos en los que se intentó probar que era posible lograrlo. El objetivo se ha ido cumpliendo paulatinamente, a veces con retrasos de décadas respecto de las expectativas iniciales. La IA ha incursionado, así, en la resolución de problemas logarítmicos, razonamientos lógicos, traducción simultánea de lenguajes y lectura automáticas de textos, reconocimiento de imágenes, así como en redes neuronales artificiales y sistemas expertos, entre otros ámbitos (Alfonseca, 2016).

En los desarrollos de estrategia para la resolución de juegos como el ajedrez, damas, póker, etc., mediante IA, se suele aprovechar la rápida anticipación de cálculo y consideración de escenarios futuros, por encima 
de los chispazos intuitivos con los que el jugador humano guía sus decisiones; pues es en la consideración de escenarios posibles y sus respectivas consecuencias donde la IA manifiesta indiscutible superioridad frente a la mente humana. Por ello muchas veces se le ha negado a la IA el carácter de verdadera inteligencia, porque en esos procesos de cálculo y estrategia opera sin comprensión de la actividad que lleva a cabo. Los grandes jugadores confiesan que en ocasiones no calculan jugadas anticipadas como todos supondríamos, sino que es la intuición la que muchas veces sugiere cuál puede ser la mejor jugada a intentar (Moreno-Dávila, 2007: 789).

En cambio, en el campo de la programación informática para conseguir procesos deductivos, la IA ha conseguido conquistas indiscutibles; aunque no en el campo de la inducción y la abducción. En otros rubros como el reconocimiento de voz, la traducción simultánea o la identificación de imágenes (que está, por ejemplo, en la base de la fabricación de autos sin conductor), los resultados a veces no han correspondido a las prometedoras expectativas con que iniciaron estos desarrollos hace décadas. Los avances más importantes llegaron con los sistemas expertos y su capacidad de hacer deducciones lógicas de acuerdo con contextos cambiantes de aprendizaje, en los que se usan diferentes criterios de procesamiento de la información. Como las variables a considerar podrían ser infinitas, los sistemas expertos hoy son capaces de cribar información de acuerdo con el problema a resolver. Lo mismo ocurre con los desarrollos de la computación cognitiva. Y es que los sistemas expertos multiplican su funcionalidad: son capaces de diagnosticar, monitorear, planificar e interpretar la información (Mello, 2002: 771).

Pero cuando hablamos de IA fuerte, es decir, la que pretende elaborar máquinas inteligentes con alcances semejantes o superiores a los de la inteligencia humana, hablamos de una búsqueda de otra envergadura. No es casualidad que hoy se cifre la esperanza de una eventual inmortalidad humana en los desarrollos de este tipo de IA, mediante los proyectos de preservación de los contenidos mentales en sistemas de cómputo inteligentes. 
Una aspiración constante de la IA es superar definitivamente la prueba de Turing, por más que la habitación china de Searle insista en que, en su versión fuerte, la IA aún está lejos de ir más allá de una imitación básica de la mente humana para alcanzar la superinteligencia prometida. Parece haber un consenso según el cual se reconocería como realmente inteligente a la máquina que pudiera entender las operaciones y procesos que ejecuta y fuera consciente de la situación en la que se halla, y no solo las máquinas que pueden obtener y procesar más rápido la información que la mente humana.

Preguntarnos qué tan natural puede parecer o llegar a ser la IA, supone que en su versión fuerte la IA ya conoce bien en qué consiste la inteligencia natural del ser humano, como para pretender copiarla en sistemas que la igualen y la lleguen a superar. El hardware ha podido emular la estructura cognoscitiva, y el software el proceso (Mello, 2002: 768); pero no parece ello suficiente, siempre y cuando se parta de una visión no reduccionista del ser humano. Porque para quienes piensan que estamos integrados por un monismo emergentista o reduccionista, la IA fuerte es ya una realidad y faltan muy pocos pasos para extenderla a cabalidad. Mientas que si partimos de cualquier variante de dualismo donde se quiera preservar lo mental como irreductible a lo biológico, la operación mental y su independencia se pretenden resguardadas, aunque quedaría mucho por explicar acerca de la interacción entre dos realidades de naturaleza tan diferente.

Preguntarnos qué tan natural puede llegar a ser o parecer la IA, quizá nos debería llevar a inquirir no solo aquello que puede lograr hacer la IA al imitarnos, sino qué podemos hacer con ella nosotros cuando la IA está a nuestra disposición, según sugiere Tirso de Andrés a quien seguiré muy de cerca en los siguientes párrafos (De Andrés, 2002: 15). Porque si los usos de la inteligencia humana acaban siendo lo mismo en su ejercicio natural que los emprendidos por un sistema de IA, en ese momento habríamos de reconocer la dilución de toda peculiaridad de nuestra existencia.

Como el ser humano está acostumbrado a superar sus propios logros transformadores a través de máquinas, es normal que se pregunte si habrá 
¿Qué tan natural es la inteligencia artificial?

algún acto de la inteligencia que sea propiamente humano, exclusivamente humano, naturalmente humano; no reproducible ni superable por la tecnología informática o robótica. O dicho al revés: si acaso de verdad es posible que la IA sea inteligente de suyo, y no por mera imitación a la inteligencia humana; como ocurre con toda inteligencia humana, que actúa de modo autónomo en cada persona.

\section{Del cómputo artificial a la naturalidad de la IA}

Parece que en vez de insistirse en la distancia que hay entre IA e inteligencia humana deberían remarcarse los logros de cada una, como base para el contraste entre ambas. La diferencia entre ellas no es un problema solo teórico, ni se puede solventar con la superficial respuesta de que las computadoras solo hacen lo que un humano le programa (De Andrés, 2002: 17). El asunto está en aclarar qué es lo que nos diferencia, lo que nos hace humanos en cuanto al ejercicio de nuestro intelecto; esto es, si hay una diferencia cualitativa entre IA y la humana, o si la biomímesis es capaz de desdibujar definitivamente la frontera entre ambas (De Andrés, 2002: 18).

Las primeras emulaciones artificiales de la inteligencia humana pretendían reproducir el razonamiento demostrativo lógico a partir de su automatización: con la propuesta de una matemática universal y la suposición de que la racionalidad humana no era sino parte de esa matemática, la automatización del cálculo solo tendría que reproducir esos procesos racionales para emular y eventualmente suplantar la inteligencia natural (De Andrés, 2002: 21). El éxito de la reproducibilidad de este tipo de razonamiento radicaba en reflejar la complejidad de llegar a una conclusión verdadera o falsa de tipo booleana (De Andrés, 2002: 23); lo que hizo pensar que cualquier problema o planteamiento lógico se podía calcular o reducir a un algoritmo computable.

Con la miniaturización de la electrónica, las operaciones lógicas proyectaron la creación de las máquinas lógicas por encima de las calculadoras 
aritméticas. Con la retroalimentación y los sistemas autoorganizados, los ordenadores en su forma moderna se abrieron paso como operadores lógicosimbólicos.

Posteriormente, los sistemas expertos sorprendieron por su capacidad de emular a los humanos especialistas en un determinado tema, y se volvieron capaces de resolver todo problema con justificación del proceso de resolución incluido: lograron adquirir información en función de teorías y experiencias acumuladas (De Andrés, 2002: 39). En su operatividad, los sistemas expertos no solo son capaces de adquirir, procesar y guardar velozmente la información, sino también de seleccionar y discriminar la más significativa de acuerdo con el asunto a resolver, a partir de la identificación del contexto del problema y sus elementos y mediante la comprensión del lenguaje simbólico y regulado que es la comunicación.

Aunque ello no implique que la forma humana de pensar sea del todo imitable por la IA, de cualquier modo, la capacidad de aprendizaje mediante ramificación de conexiones (De Andrés, 2002: 47), en el caso de las redes neuronales artificiales, mostraron que no era necesario programarlas, sino que a partir de ensayo y error y el análisis de la particularidad de cada caso, el sistema era capaz de resolver problemas al modo humano. Esto es, aprender de la experiencia, flexibilizar un proceso, generalizar rápidamente, identificar y asumir fallos en el proceso de adquisición, gestión o incremento de conocimiento, etc. Y ante este avance, para evitar confusiones, es que se insiste en contraste que el tratamiento humano de información es intuitivo, asociativo y holístico; no únicamente lógico-formal-simbólico (De Andrés, 2002: 55).

El teorema de Gödel planteó que existían verdades a las que la máquina no podría llegar y la inteligencia humana sí. Por lo que a partir de su formulación se enfatizó ese carácter limitativo como la diferencia más grande entre la IA y la humana. Pero, insistamos con Tirso de Andrés: haber identificado la limitante de la IA no quiere decir haber encontrado el modo humano de ser inteligente. Las limitantes también podrían ocurrir en el ser humano. Por ello 
es fundamental encontrar si hay un ejercicio del pensar que sea solo humano, y si homologándose, la IA podría hacerse pasar por natural (De Andrés, 2002: 67). Es decir, el planteamiento a dilucidar es si la máquina puede realmente pensar y no solo adquirir, almacenar y procesar información; capacidades en las que son indiscutiblemente superiores a los humanos.

La expectativa de que la IA hubiera logrado reproducir a cabalidad la inteligencia humana pasa por considerar ésta como un mero ejercicio racional de manejo y aprendizaje de símbolos formales y demostraciones deductivas e inductivas, en lo que, como se ha recalcado, las máquinas han resultado más racionales que el ser humano (De Andrés, 2002: 80). Pero al parecer tendríamos serios elementos para concluir que nuestra inteligencia no parece radicar en un mero ejercicio racional. Los ordenadores manipulan símbolos de acuerdo a programas previos; por lo que la ejecución de los programas que hace la máquina inteligente no parece implicar un ejercicio que pudiéramos llamar en sentido estricto cognición: porque en la mayoría de los casos reproduce la sintaxis, pero no la semántica.

Si advertimos cómo opera la red neuronal humana, notaremos que ajusta su semántica por medio del aprendizaje: desde niños el humano explora, juega, ensaya, corrige al contrastar su cuerpo con el ambiente que le rodea, como un todo enfrentado a otro todo: revela una inteligencia emocional alegre, irritable, insatisfecha, ilusionada, serena, destrozada, tranquila (De Andrés, 2002: 90). Pero cuando aparece el lenguaje, con sus palabras y símbolos, el contacto con la realidad no se lleva a cabo de modo crudo y directo, mediante los sentidos externos; ni de manera sentimental mediante los internos. Se lleva a cabo mediante signos y símbolos formales, que sólo tienen la semántica y sentimientos que les asignamos.

En ese sentido, tanto el ser humano como un ordenador manipulan símbolos, aunque el humano sabe que solo trata con signos y símbolos. Cuando los animales tratan eficazmente con información, sobreviven, pero no conocen que conocen, y por ello no hay espacio para la rectificación radical en la acción, porque en ello podría irle la sobrevivencia. En la reflexión mental humana, 
en cambio, paramos, reparamos y consideramos si las ideas que formulamos sobre un asunto en particular son las adecuadas, y en caso contrario cuál es el camino para ajustarlas. Como lo hago en este momento al escribir y reescribir las expresiones que reflejen lo que verdaderamente deseo comunicar. Conciencia e intencionalidad se revelan por tanto como los factores por los que el yo es consciente del yo.

Pero la inteligencia no parece identificarse con la sola conciencia, a riesgo de convertir nuestro intelecto en mera pasividad del sujeto. Por más que al "tomar conciencia" reconsideramos la acción con un sentido claramente práctico, la inteligencia no es una mera consciente receptividad pasiva de ideas, impulsos o sentimientos (De Andrés, 2002: 107-113). La conciencia se ejerce como una habilidad reflexiva sobre nuestras ideas; por ella advertimos que la información no es sino información. Y cuando eso ocurre, los signos y símbolos propios del lenguaje y la comunicación se muestran como no referidos solo a ellos mismos sino a una realidad manifestada fuera (intencionalidad). Cuando el ser humano se pregunta, sabe que las preguntas solo son preguntas, que habrá de ajustarlas, corregirlas, suspenderlas o elaborarlas porque sabe que lo conseguido no es toda la información a adquirir, y ello solo puede ser logrado por un ejercicio de la conciencia.

Máquinas y animales son intencionales y requieren y adquieren información. Si en el ejercicio intelectual humano no hay algo más, se corresponderá con el saber animal o informático. Pero parece que hay mucho más en el intelecto humano: nuestra subjetividad se ve impresa en la admiración, raíz del avance en el conocimiento. Un saber a partir del cual no se buscar ir más allá refleja una perplejidad paralizante, más que un asombro fecundo que inspire nuevas preguntas inagotables para saber más y mejor sobre algo. En la intencionalidad animal lo fundamental es adecuarse a la realidad; no puede prescindir hacer lo que le viene a la cabeza, a fin de cristalizar sus objetos mentales para garantizar la sobrevivencia (De Andrés, 2002: 203).

Pero la inteligencia humana va a más. No se detiene en solo conclusiones. Tener solo respuestas y no nuevas preguntas es un fracaso 
antropológico, pues preguntar es una sana señal de saber poner entre paréntesis lo ya sabido para explorar más. Aristóteles propuso en sus Segundos Analíticos que el interés humano podía resumirse en las preguntas sobre el hecho, su porqué, su existencia y su esencia. Y así, nuestra habilidad reflexiva por la que poseemos, dominamos o dirigimos nuestra información (y sabemos que es solo información), se combina con la curiosidad que nos lleva a nuevas preguntas sobre la realidad toda, y sobre el todo de cada realidad (porque cuando se considera algo en sí mismo, como lo hace nuestra inteligencia, interesa todo ente). Este ejercicio intelectual se revela como signo típicamente humano, sujeto a crecimiento y mejora; porque el humano existe en un mundo, no solo en un entorno. De ahí su interés por lo inútil y lo que no conlleva rentabilidad evolutiva, porque ser persona es ser un animal de novedades (De Andrés, 2002: 135, 175).

La racionalidad humana es mucho más que conclusiones y procesos deductivos, que son la fuente en buena medida de la IA. La inteligencia humana no solo resuelve problemas: los crea y se mete en más problemas; no porque quiera complicarse la existencia, sino como una manera de reconocer la complejidad del mundo que le rodea con sus plurales aspectos. La mente humana halla y prosigue. Por ello la libertad se revela de modo especial en la capacidad de producir nuevas ideas, proyectos, formas de pensar. Ser humano es pensar y hacer proyectos, considerando nuevas posibilidades, porque al descubrir que las ideas son solo ideas, el hombre revela libertad dentro de su mundo (De Andrés, 2002: 197, 202, 205). Ese es el verdadero rasgo que si fuera poseído por la IA merecería el reconocimiento de natural.

Por este carácter libre, la inteligencia humana se interesa no solo en la lectura omnicomprensiva y totalizante de la realidad, sino en la advertencia de las nuevas posibilidades creativas que aparecen cuando la inteligencia considera en perspectiva dicha realidad y las relaciones que en ella se dan entre una cosa y otra.

La inteligencia es una facultad que advierte conexiones e interacciones significativas; con la intención de aportar, enriquecer, incrementar o variar, 
tanto la comprensión como la incidencia en las interacciones reales (reconocer, conservar, perfeccionar). Ello exige una consideración teleológica del mundo que rodea al hombre, pues la perfección es la manera de aumentar ese orden, de ganar en capacidades, de acertar en los blancos. Por lo que el aumento en el conocimiento conlleva el incremento en la capacidad creativa humana.

Como la subjetividad es más que la mera conciencia, advertir mi presencia solo es fecundo para la inteligencia humana cuando le lleva a considerar quién, cómo y por qué puedo llegar a ser quien deseo ser: no somos mera autoconciencia ni espontaneidad, sino subjetividad y libertad creativa, lo cual permea intrínsecamente en nuestra inteligencia. Por eso el carácter estereotipado de conducta va más con el carácter animal que con el humano. La espontaneidad, paradójicamente, no es signo de libertad, pues actuar sin supuestos condicionamientos como la educación, la cultura, las circunstancias personales, nos dejaría a merced de la mera pulsión de la determinación natural, reglada, establecida, definida, evolutiva y cambiante.

Y cuando hablamos de inteligencia, no parece que la espontaneidad sea el rasgo que más le haga justicia, pues el hombre suscita, controla, detona, dirige, sus actividades mentales (De Andrés, 2002: 267); no solo las experimenta como pulsiones espontáneas sin ley. No parece que las redes neuronales informáticas operen al modo intelectual humano, pues de una manera determinada avanza en la identificación de conexiones informáticas, sin necesidad de una inútil reflexión acerca del porqué hay lo que hay; únicamente operan lo que hay, en función de lo que hay.

En cambio, los hábitos humanos, entre los que se encuentran los de carácter intelectual, permiten al sujeto no solo ejercer su conocimiento intelectual, sino buscar un equilibrio ideal o feed-back para preservar lo bien ejercido o conocido y combinarlo con un feed-before, que aluda a la posesión y destinación futura que proyecta, corrige, mejora y emprende las decisiones pensadas. Así, la práctica o ejercicio genera potenciación y crecimiento. Y en el campo del conocimiento, conlleva pararnos, detenernos a pensar, y pensar en serio; para conocer a fondo y comprender deverdad; al margen de 
¿Qué tan natural es la inteligencia artificial?

la mera adquisición ingente de información o el procesamiento metódico estandarizado.

Los hábitos del conocimiento se revelan en la persona, por tanto, detonadores de nuevas realidades, de donde parte su crecimiento. Las solas habilidades racionales por las que de modo casi técnico pasamos de un conocimiento a otro sin que se requiera comprensión de lo hilado, son la fuente de la imitación informática de la IA. Actividades mentales humanas de carácter reglado, procesual, metódico, cuya finalidad es arrojar resultados y conclusiones, son compartidas con animales y sistemas informáticos que adquieren y procesan información en búsqueda de resultados. En ello radican las habilidades racionales, que son mucho mejor emprendidas y ejecutadas por las máquinas racionales de la IA.

\section{Racionalidad versus entendimiento}

A veces sentimos que los desarrollos de la ciencia van más deprisa que su regulación jurídica; y es que la ciencia avanza en la adquisición y procesamiento de información (que se acelera al incrementarse la velocidad de su transmisión y codificación); mientras que el derecho, como otras disciplinas que requieren reflexión, se paran a considerar qué podría ser justo o no. Este es un ejemplo más de la diferencia entre habilidades racionales y hábitos intelectuales. Las habilidades racionales avanzan, se eficientizan, cambian, evolucionan, sin que se requiera pensar: nos ha pasado con la transformación energética, la revolución industrial y la tecnologización de la sociedad. Hemos avanzado en ello a pasos agigantados en su eficacia y eficiencia sin que nos preguntáramos durante siglos para qué o por qué transformábamos la realidad. Solo ahora, dentro de las crisis ambientales, las hambrunas y el cambio climático nos hemos parado a reflexionar qué hemos hecho. Crecíamos en las habilidades racionales, en el saber que da poder, sin entender qué es lo que sabíamos y podíamos, propio de los hábitos intelectuales. La IA parece ocuparse preferentemente de la imitación 
de las habilidades racionales y desentenderse de los hábitos intelectuales; tan difícilmente imitables, por requerir de reflexión consciente.

Los modos de razonar, esto es, las habilidades racionales, son un camino en la ruta de la eficiencia y eficacia de la adquisición y procesamiento de información; son métodos del conocer, pero no del pensar. Hacer preguntas sobre lo conocido va más allá de la razón misma, de la habilidad racional, en la que se detiene la informática y la cibernética. Hacerse meta-preguntas sobre esos métodos de adquisición y procesamiento de información, me lleva a una meta-ciencia, una meta-lógica, una metamatemática, que permite poseer y dirigir la razón (siempre instrumental) y sus resultados. Ese ejercicio de entendimiento es a lo que estamos llamando hábitos especulativos: la razón requiere ser dirigida; mientras que el intelecto dirige y permite actuar bien, o discurrir bien. Es decir, pensar acertadamente, sensatamente, con el aumento de la capacidad de comprender que ello conlleva.

Nacemos con el empeño de querer entender (eso que el pensamiento aristotélico llamó primeros principios), en virtud de lo cual advertimos que las realidades poseen una cierta distinción unas respecto de otras (principio de identidad), y se muestran contrastadas entre sí (principio de no contradicción) y en interacción mutua (principio de causalidad). El ejercicio de ese empeño se vuelve habitual y hace que nuestra inteligencia esté preparada para enterarse y comprender el mundo que tiene enfrente. Eso convierte nuestra mente en una inteligencia libre que inventa, domina, armoniza, dirige, las habilidades racionales (De Andrés, 2002: 306) y las convierte no solo en ejercicio de obtención de información sino en fuente de entendimiento; porque no se sujeta a ella, sino que se adueña, se enseñorea de ella.

Y ello supone una subjetividad consciente más inteligente y libre, no automatizada y rígida (como ocurre con las habilidades racionales). Una subjetividad ordenada, articulada, profunda, virtuosa genera una objetividad mental eficaz y veraz. Si aprendemos a obtener y cultivar hábitos intelectuales, y no solamente a practicar destrezas mentales o racionales, reconoceremos en dicho acto lo más originariamente humano: nuestra capacidad e interés por comprender, no solo por concluir. 
¿Qué tan natural es la inteligencia artificial?

Este perfeccionamiento del entendimiento, del ejercicio de los hábitos intelectuales originarios del ser humano, solo puede potenciarse en el intercambio de pensamientos, en el dialogo, en el abandono del solipsismo y el autismo intelectual. Porque paradójicamente las habilidades intelectuales se adquieren de afuera hacia adentro: primero convivimos, interactuamos, reconocemos mutuamente la subjetividad que poseemos al compartir la subjetividad de los demás; y así, al reforzar la interacción con otras personas, interiorizamos y dominamos nuestras herramientas racionales para convertirlas en fuente de entendimiento intelectual. No auto programamos, dominamos y dirigimos nuestra capacidad de obtener y procesar información sin la comunicación interpersonal en la convivencia y el lenguaje (De Andrés, 2002: 317). Es el carácter interpersonal de la adquisición, dominio y desarrollo del conocimiento operacional, en lo que radica precisamente la cultura. Por eso, una cultura que muere no consiguió mantener su carácter detonante de dominio y crecimiento de nuestra capacidad de entender el mundo, y se va diluyendo poco a poco para dar a pie a otras interpretaciones más competitivas sobre la realidad.

Por lo tanto, las máquinas racionales (cuyas destrezas en la obtención y procesamiento de información son superiores a las del ser humano), nos harían pensar que al rebasar al hombre desdibujarían qué de específico tienen el conocimiento humano, y haría pasar por natural su operación informática tanto como lo es el razonamiento humano.

Entonces, ¿̇somos verdaderamente peculiares? Si la respuesta es negativa, debemos afirmar que no somos solo devoradores y procesadores de información (informávoros aturdidos, les llama De Andrés, 2002: 325), sino generadores de buenos hábitos intelectivas, al tiempo que dialogantes interpersonales.

Si realmente pretendemos navegar exitosamente en la sociedad de la información o del conocimiento (que también puede ser la sociedad de la ignorancia, del aturdimiento y la perplejidad paralizante), y queremos realmente una sociedad de inteligentes, habremos de transitar desde la 
adquisición y desarrollo de las habilidades racionales, hacia una subjetividad comprometida.

Y ello implica recibir en el dialogo una subjetividad que para ser entendida y entender habrá de ejercer una meta-lógica, una meta-racionalidad llamada hábitos intelectuales; y no solo recitar coordinada y coherentemente los contenidos mentales como lo haría un super computador ante el que nunca aprobaríamos el test de Turing.

Para crecer en objetividad y mostrar que somos mucho más que simples generadores de habilidades racionales superables por la IA, debemos apuntalar la subjetividad, devolviendo a la persona su protagonismo en el conocimiento; con una subjetividad más cultivada y crecida. Con un relativismo bien entendido: en el que en lugar de reducir el conocimiento al método de adquisición de información más eficaz (racionalidad), lo remita a la subjetividad, a la persona individual y completa (intelecto) (De Andrés, 2002: 323).

El carácter social, intrínseco a nuestra naturaleza implica no solo la mutua dependencia entre humanos para conseguir la comunicación, la participación de los bienes y la vivencia común de experiencias, sino también para el dominio de las operaciones cognoscitivas (que no se alcanzan en soledad y sin dialogo) y su crecimiento (imposible de alcanzar sin cultura). Lo que convierte al carácter interpersonal en el rasgo más fundamental y definitivo que permite el despliegue de la racionalidad como cultura.

Se piensa muchas veces que el enfoque en el sujeto fue uno de los rasgos distintivos de la modernidad, cuando al parecer habría sido más característico de ella su insistencia en el método. En contraste, es el involucramiento del sujeto y su protagonismo dentro del conocimiento el que hace inevitable un sano relativismo: porque todo conocimiento debe ser relativo, no al objeto mental, como quería la modernidad, sino a la persona: con toda la riqueza de la subjetividad que le caracteriza. Solo el que considera sus subjetivas y parciales limitaciones cognoscitivas es capaz de apostar por su propio crecimiento intelectual, mediante un ejercicio serio de los hábitos 
¿Qué tan natural es la inteligencia artificial?

correspondientes. El miedo al relativismo se debe a un excesivo énfasis en la verdad objetiva, cuando en realidad es en la referencia al sujeto que se logra una comprensión cabal de la realidad, cuando la persona se ocupa de crecer en sus capacidades racionales y en el ejercicio de sus virtudes intelectivas; porque solo la vida inteligente puede ser vida verdaderamente humana. El conocimiento no es amoral, es fundamentalmente ético: nuestra primera obligación es para con la conquista de la libertad de nuestra propia inteligencia, que al enseñorearse de las ideas y métodos mentales es capaz de cumplir sus más altos anhelos cognoscitivos (De Andrés, 2002: 333-341)

Si solo nos enfocáramos en el método, no podríamos responder a la pregunta sobre cuál puede ser el rasgo cognoscitivo diferencial de los seres humanos frente a la IA y las capacidades cognoscitivas animales. Hoy podemos responder que la gran diferencia entre las máquinas inteligentes y el ser humano radica en nuestra posibilidad de cultivo del dialogo como base para adquirir los hábitos intelectuales que nos permitan conquistar la libertad de nuestro pensamiento; porque las máquinas racionales no poseen en realidad el conocimiento que imitan y reproducen, y mucho menos cuentan con la libertad de conocer.

\section{Lo natural a imitar en la IA}

Es muy difícil responder con una fórmula tajante casi unívoca (tan de estos días) a la pregunta acerca de cuál es rasgo natural que pretende ser igualado y superado por la IA en su versión fuerte. Es decir, en qué consiste la naturaleza humana y qué papel juega en ella el ejercicio intelectual que la IA igualará y suplantará. Cuando la naturaleza humana se piensa como un catálogo de características típicas o distintivas en todos los humanos por igual, surgen los problemas para aclararnos de qué estamos hablando cuando afirmamos que la IA puede mostrarse natural (Hannon, 2018).

Hay quienes sugieren que un concepto tan manido a lo largo de la historia filosófica como el de naturaleza humana, debería dejar paso a otras 
formulaciones no tan discutidas por sospechosas de fijismo esencialista; y en cambio proponen modos de entender la naturaleza humana donde se articule mejor la presencia del sujeto junto a su dinamismo biológico. Según esta iniciativa, el concepto de estructura de subjetividad parecería reflejar mejor lo que nos caracteriza (Rodríguez, 2017) porque da cuenta del constitutivo corporal propiamente humano, generador de técnica, potenciador de transformaciones del entorno y creador de modos de entender el mundo (estructura). Peculiaridades en conjunción con la capacidad de empatizar con el otro, expresar la interioridad de los pareceres y convicciones más íntimos y ponerlos en común mediante la sociabilidad (subjetividad). Para esta perspectiva, la IA no tendría posibilidad de una imitación y suplantación radical de nuestra inteligencia, pues, aunque reprodujera la estructura, se le escaparía la subjetividad; a menos que se entendiera por tal la irrepetibilidad del código de barras de la máquina inteligente. Y así, no podría jamás considerarse natural la IA.

Algunos otros autores insisten en una peculiaridad humana que escaparía (por su singularidad) a cualquier ejercicio de objetivación homologadora de la IA: la conciencia, imposible de ser explicada como el resto de las realidades a las que el intelecto tiene acceso. Una suerte de realidad inefable por diferente e irreductible (Arana, 2015). La IA no tendría, así, oportunidad de hacerse del carácter humano y mucho menos de superarlo, dada la improcedencia de reducir a lo biológico esa dimensión autotransparente de la vida psíquica llamada conciencia, en virtud de la cual, según Juan Arana, el sujeto pensante se convierte en espectador activo de sí mismo, y se ve protagonista y responsable de sus actos (Arana, 2015: 9).

Para otros más, la naturaleza humana es una fecunda combinación de varias dimensiones en las que se entrelazan la corporeidad, la racionalidad y la sociabilidad. De dichas dimensiones se desprenderían las realidades más profundamente humanas, imposibles de ser replicadas o suplantadas por versión cualquiera de la IA. Según esta visión, del carácter corpóreo se desprendería la condición humana de vulnerabilidad, tanto biográfica (por 
¿Qué tan natural es la inteligencia artificial?

temporal) como biológica. De la racionalidad se derivaría la creciente autonomía respecto del mundo que la inteligencia va mostrando tanto en la ciencia como en la técnica, al no depender de la adaptación al medio y poder hacerse de todas las cosas mediante el conocimiento, como decía Aristóteles. Y de la sociabilidad se derivaría nuestro carácter relacional, por el que comunicamos interioridad e intimidad vivida en la singularidad del yo inconfundible que somos cada uno (Marcos, 2018: caps. 1-3).

Bajo esta perspectiva, la IA tampoco podría mostrarse en modo alguno natural o suplantadora de la natural: los actuales desarrollos de la IA fuerte evitan la vulnerabilidad temporal biográfica como rasgo de imitabilidad, y apuestan en todo caso a la inmortalidad del conocimiento convertido en código binario vaciado en super cerebros computacionales (transhumanismo). La autonomía racional sí que sería emulable, aunque en la propuesta que la considera fundamental para la naturaleza humana, no es separable de la vulnerabilidad corpórea y la dependencia social. Y la sociabilidad tampoco entraría en los intereses de la IA, pues más que dependencia en todo caso se emularía la interacción ausente de compromiso de compartir una intimidad que no se puede generar mediante IA.

\section{Conclusión. ¿Quué tan natural puede llegar a ser la IA?}

Se ha sugerido a lo largo de este texto que no parece plausible el que la IA pueda llegar a presentarse como intercambiable con la intelección humana, como si sus procesos pudieran pasar por naturales, tanto como lo son nuestro ejercicio intelectual de comprensión de la realidad.

Se ha mencionado como razones de esa no plausibilidad la diferencia entre la capacidad humana de adquisición, proceso e incremento de información, llamado racionalidad (que sería imitable y ampliamente superable por las máquinas racionales), respecto de las habilidades intelectuales que se ejercen para entender la realidad, no solo para derivar una premisa de otra silogísticamente. Porque la IA no pretende ni requiere comprender 
para computar, aprender, gestionar y optimizar la información que se genera en sus procesos.

¿Y por qué esa frontera infranqueable entre IA e imitabilidad y superación del intelecto humano? Quizá porque se ha desdibujado un poco que la perspectiva desde la cual la IA aborda la actividad intelectual humana no es unívoca y requiere de una reubicación conceptual.

El conocimiento neurocientífico de la operatividad cerebral del ser humano opera desde la perspectiva de la tercera persona; mientras que lo más íntimo de nuestra operación mental, esa que solo es autotransparente al sujeto en el que se da, pertenecen a la perspectiva de la primera persona. En la dimensión de la primera persona, nos sabemos autoconscientes, autoreflexivos, autoorganizados en una biografía por la que advertimos que sabemos que existimos, sabemos quiénes somos y qué hacemos. Esto no está en el escenario de la IA porque para funcionar ésta no requiere de una singularidad biográfica del procesamiento acelerado de información que elabora. Y lo mismo puede decirse de los sistemas expertos y las redes neuronales artificiales.

Nuestra presencia biográfica abordable desde la primera persona es manifestativa y receptiva hacia otros yo con los que coexistimos y mediante lo cual penetramos en la intimidad del otro y manifestamos la intimidad que nos constituye desde dentro. Este conocimiento se alcanza desde la perspectiva de la segunda persona.

Cuando la IA pretende emular, superar y suplantar el carácter singular del ser humano, se está relativizando la riqueza de estas tres perspectivas, para reducirla a una sola mediante un ejercicio de naturalización del conocimiento. Se trata de un reduccionismo de la riqueza humana a la perspectiva de la tercera persona.

Cuando lo que se pretende es convertir el yo en la única realidad existente en el ser humano e imitable por la IA, estamos hablando del subjetivismo propio de la reducción a la primera persona.

Y cuando olvidamos el carácter individual, único, irrepetible de cada uno de nosotros, estamos ante un reduccionismo de la segunda persona (Pérez 
¿Qué tan natural es la inteligencia artificial?

de la Borda, 2018, cap. 3), que se pretende posible en los últimos desarrollos de la IA.

Y de este modo, es que a partir de diferentes ejercicios de reduccionismo (curiosamente fruto de la operatividad intelectual) es que hemos desdibujado los alcances, límites y expectativas reales de las variantes de la IA. Comprender esto (no solo inferirlo), calibrarlo, sopesarlo, puede ayudarnos a atemperar falsos reduccionismos, pero también injustificados temores. La IA seguirá dotándonos de herramientas para no depender de nuestra limitada capacidad dianoética, pero seguirá estando a nuestra disposición para ser dimensionada en el lugar prioritario que concluyamos dependiendo de las circunstancias sociales, culturales y tecnológicas, que decidamos de acuerdo con el ejercicio consciente y reflexivo de nuestros hábitos intelectuales. Y para ello no hay mímesis biológica que sea suficiente.

\section{Bibliografía empleada}

M. Alfonseca, "Inteligencia artificial”, en C. Vanney, I. Silva, F. Franck, F. (editores), Diccionario Interdisciplinar Austral, 2016. URL $=$ http://dia.austral.edu.ar/Inteligencia_artificial

J. Arana, La conciencia inexplicada. Ensayo sobre los límites de la comprensión naturalista de la mente, Madrid, Editorial Biblioteca Nueva, 2015.

Aristóteles, Física, México, UNAM, 2001.

M. Bedau, C. Cleland, La esencia de la vida. Enfoques clásicos y contemporáneos de filosofía y ciencia. México, Fondo de Cultura Económica, 2016.

J. Benyus, Biomímesis. Cómo la ciencia innova inspirándose en la naturaleza. México, Tusquets, 2012.

B. Bensaude-Vincent, W. Newman, (editores), The Artificial and the Natural. An Evolving Polarity, Cambridge, Massachusetts, USA, The MIT Press, 2007.

T. De Andrés, Homo Cybersapiens. La inteligencia artificial y la humana. Pamplona, España, EUNSA, 2002.

E. Hannon, T. Lewens, (editores), Why We Disagree About Human Nature, Oxford, United Kingdom, Oxford University Press, 2018.

A. Marcos, M. Pérez, Meditación de la naturaleza humana. Madrid, España, BAC, 2018.

P. Mello, "Intelligenza artificiale", en G. Tanzella-Nitti, A. Strumia, (editores), Dizionario Interdisciplinare di Scienza e Fede, Città del Vaticano, Urbaniana University Press, 2002, vol. 1: 767-781 


\section{Héctor Velázquez}

J. Moreno-Dávila, "La inteligencia artificial”, en A. Segura (editor), Historia Universal del Pensamiento Filosófico, Ortuella, España, Liber Distribuciones Educativas, 2007, vol. V: 781 797.

M. Pérez de Laborda, F. Soler, C. Vanney, (editores), ¿QQuiénes somos? Guestiones en torno al ser humano. Pamplona, España, EUNSA, 2018.

F. Rodríguez Valls, Orígenes del hombre. La singularidad del ser humano. Madrid, España, Biblioteca Nueva, 2017.

\section{Héctor Velázquez Fernández} hv_mx@yahoo.com.mx 